\title{
A URBANIZAÇÃO COMPROMETE A QUALIDADE DA ÁGUA DA BACIA HIDROGRÁFICA DOS RIOS VACACAÍ E VACACAÍ-MIRIM EM SANTA MARIA, RS
}

\author{
URBANIZATION JEOPARDIZES WATER QUALITY IN VACACAÍ AND \\ VACACAÍ-MIRIM HYDROGRAPHIC BASIN, SANTA MARIA, RS, BRAZIL.
}

\author{
Mariana Durigon ${ }^{1}$, Maria Angélica Oliveira², Delmira Beatriz Wolff 3 , Ana Paula Vestena Cassol', \\ Juliana Ferreira da Silva ${ }^{5}$ \\ 1,4,5Mestre, Programa de Pós Graduação em Agrobiologia, Universidade Federal de Santa Maria, Santa Maria, \\ Brasil \\ ${ }^{2}$ Doutora, Departamento de Biologia, Universidade Federal de Santa Maria, Santa Maria, Brasil \\ ${ }^{3}$ Doutora, Departamento de Engenharia Sanitária e Ambiental, Universidade Federal de Santa Maria, Santa \\ Maria, Brasil
}

\section{Resumo}

A bacia hidrográfica dos rios Vacacaí e Vacacaí-Mirim no município de Santa Maria possui em alguns pontos grande influência antrópica, com isso esse trabalho foi conduzido com o objetivo de avaliar a qualidade das águas nestes rios por meio de variáveis físicas e químicas da água. As amostras foram coletadas em seis pontos e a avaliação foi feita mensalmente durante um período de doze meses (junho de 2011 a junho de 2012). Efetuou-se análises de demanda bioquímica de oxigênio (DBO5), demanda química de oxigênio (DQO), pH, sólidos suspensos (SS), condutividade, turbidez e oxigênio dissolvido. Os parâmetros foram comparados com as classes de uso da água prevista na resolução do Conselho Nacional de Meio Ambiente (CONAMA 357/2005). Foi realizada uma análise de componentes principais $(A C P)$, visando identificar a interação entre as variáveis abióticas. Pode-se observar uma associação espacial dos parâmetros em relação às amostragens, evidenciando os efeitos da urbanização na qualidade da água.

Palavras-chave: ecossistemas lóticos, variáveis abióticas,Vacacaí, Santa Maria, qualidade da água

\begin{abstract}
The hydrographic basin of the rivers Vacacai and Vacacai-Mirim, in Santa Maria, RS, Brazil, is subjected to strong anthropic influence, and the study here described aimed at evaluating water quality in these rivers using physical and chemical analyses. Water samples were collected in six sampling stations, monthly for 12 months (June 2011 to June 2012). Biochemical oxygen demand (BOD), chemical oxygen demand (COD), $\mathrm{pH}$, suspended solids (SS), conductivity, turbidity and dissolved oxygen were measured. The results were compared to the classes of water use given by the National Environment Council in the Resolution 357/2005. A principal components analysis (PCA) was performed in order to identify the interaction among the abiotic variables. A spatial association of the variables was visible, rather than grouping by sampling date, indicating effects of urbanization on water quality.
\end{abstract}




\section{Introdução}

A

água constitui o insumo essencial a todas as formas de vida existentes no planeta, entretanto, nos últimos anos vem-se verificando a crescente exploração e degradação deste recurso natural.

As propriedades físicas, químicas e biológicas de um rio são influenciadas pelas condições climáticas e por atividades antrópicas que ocorrem na bacia hidrográfica, em grande parte pelo lançamento de esgotos. De acordo com Guimarães e Nour (2001), o aumento da carga orgânica acarreta aumento da demanda bioquímica de oxigênio (DBO) e da demanda química de oxigênio (DQO) e consequentemente, diminuição da concentração de oxigênio dissolvido (OD), como resultado, principalmente, do metabolismo de microrganismos aeróbios.

A qualidade da água pode ser avaliada por meio de vários parâmetros, que expressam as suas principais características físicas, químicas e biológicas. Estes parâmetros podem ser: turbidez, potencial hidrogeniônico $(\mathrm{pH})$, condutividade elétrica, oxigênio dissolvido (OD), sólidos suspensos, DBO, DQO, entre muitos outros.

A turbidez e os sólidos suspensos apresentam significados semelhantes em termos de qualidade de água. Referem-se à concentração de partículas suspensas presentes na massa líquida. A turbidez indica a dificuldade de um feixe de luz passar através da água que é proporcional a presença de partículas em suspensão (LIBÂNIO, 2005). Já os sólidos representam todas as impurezas presente na coluna d'água com exceção dos gases dissolvidos. Concentrações elevadas de sólidos em suspensão reduzem a passagem de luminosidade, afetam organismos bentônicos e desequilibram as cadeias tróficas (TAVARES, 2005).
A condutividade elétrica também está relacionada com a presença de substâncias dissolvidas que se dissociam em ânions e cátions. É a capacidade que a água apresenta de conduzir corrente elétrica. De acordo com Libânio, (2005) é um indicador do lançamento de efluentes, por se relacionar à concentração de sólidos dissolvidos.

Já o pH, apresenta uma escala de variação entre 0 e 14, dando uma indicação da condição de acidez, neutralidade ou alcalinidade. É um indicativo da concentração de íons $\mathrm{H}+$ que pode ter origem natural a partir da dissolução de rochas, dos processos de fotossíntese e da oxidação da matéria orgânica, ou pode ter origem antropogênica, a partir de despejos domésticos e industriais.

Quando se trata da avaliação da matéria orgânica na água, os parâmetros mais utilizados são a DBO a DQO e o oxigênio dissolvido (OD). O oxigênio dissolvido é um importante indicativo da presença de matéria orgânica na água, pois, durante a estabilização da mesma, as bactérias fazem uso do oxigênio nos seus processos respiratórios. É fundamental para a manutenção de vida dos organismos aeróbicos, (VON SPERLING, 2005). A quantidade de oxigênio dissolvido na água varia conforme a altitude e a temperatura, considera-se que ao nível do mar e a uma temperatura constante de $20^{\circ} \mathrm{C}$ a saturação é igual a 9,2 mg/L. Quando os valores de OD superam a saturação é um indicativo da presença de algas e quando são menores é uma evidência da presença de matéria orgânica. Peixes são organismos mais sensíveis à variação de $\mathrm{OD}$, geralmente não conseguem sobreviver quando os valores forem igual a 2 $\mathrm{mg} / \mathrm{L}$ e valores iguais a $0 \mathrm{mg} / \mathrm{L}$ tem-se condições de anaerobiose (VON SPERLING, 2005).

A DBO e a DQO constituem determinações indiretas da matéria orgânica carbonácea, pois quantificam o consumo de oxigênio dissolvido (OD) pela oxidação da matéria orgânica que é o efeito principal dos compostos orgânicos no ambiente aquático. 
A proteção dos recursos hídricos é essencial para assegurar a qualidade da água para consumo humano e o equilíbrio ecológico do planeta. Neste sentido a resolução do Conselho Nacional de Meio Ambiente (CONAMA 357/2005) estabelece a classificação dos corpos de água no Brasil. Esta resolução classifica as águas doces em cinco classes diferentes, cada classe possui valores máximos admissíveis de parâmetros e condições que devem ser respeitadas, para a proteção da qualidade da água. As classes relacionam os usos das águas, que incluem desde águas potáveis para consumo humano até baixos padrões de potabilidade, destinada somente para navegação e paisagismo.

Com o desenvolvimento das indústrias e o crescimento populacional do município de Santa Maria, torna-se importante conhecer os efeitos das ações antrópicas sobre a qualidade da água da Bacia hidrográfica dos Rios VacacaíVacacaí Mirim, pois se percebe uma intensa urbanização da área e possível lançamento de efluentes domésticos e de atividades diversas.

Diante da importância dos recursos hídricos para a manutenção do equilíbrio biológico dos ecossistemas e da necessidade de preservar esse recurso para as futuras gerações, torna-se importante conhecer os parâmetros abióticos para que possam ser tomadas medidas visando à melhoria de sua qualidade. Portanto, o objetivo principal deste trabalho é fazer uma caracterização física e química da qualidade da água na Bacia hidrográfica dos Rios VacacaíVacacaí Mirim no município de Santa Maria, RS.

\section{Materiais e Métodos}

\subsection{Caracterização da área de estudo}

$\mathrm{Na}$ figura 1 observam-se as Bacias hidrográficas que fazem parte do Estado do RS, com destaque para a Bacia hidrográfica do rio Vacacaí na região central do Estado onde estão localizados os seis pontos de amostragem utilizados no desenvolvimento do estudo.
A área de estudo compreendeu a Bacia Hidrográfica dos Rios Vacacaí - Vacacaí Mirim. Essa Bacia faz parte da região hidrográfica do Guaíba, localizada na porção centro-ocidental do Estado do Rio Grande do Sul (Figura 1). Está situada entre as coordenadas geográficas: $29^{\circ} 35^{\prime}$

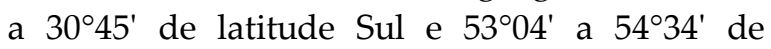
longitude Oeste. Segundo a SEMA (2012), essa Bacia abrange as províncias geomorfológicas Depressão Central e Escudo Sul Rio-Grandense e possui uma área de $11.077,34 \mathrm{~km}^{2}$, com uma população total de 384.657 habitantes, abrangendo municípios como Caçapava do Sul, Júlio de Castilhos, Santa Maria e São Gabriel. Os principais usos da água se destinam a irrigação, dessedentação de animais e abastecimento público.

As coletas foram realizadas no município de Santa Maria. Foram selecionados seis pontos de amostragem, destes somente um ponto tem como localização o Rio Vacacaí. Este ponto (P1) localiza-se no trecho médio do rio, na altura do distrito de Passo do Verde, na ponte da rodovia BR 392, têm grande influência de atividades agrícolas, especialmente culturas de soja e arroz. Os demais pontos de amostragens localizam-se no rio Vacacaí-Mirim. Destes, foi escolhido um ponto (P2), onde as influências antrópicas são menores, em uma área pouco impactada segundo o estudo de Gastaldini et al. (2006), localizada à montante do reservatório do DNOS, no Bairro Campestre, representando um afluente de primeira ordem do Rio Vacacaí-Mirim. Ainda à montante do reservatório foi localizado outro ponto (P3), no curso principal do Vacacaí-Mirim na ponte da Rua Vereador Antônio Dias que possui influência de habitações bastante próximas. Outro ponto está localizado no Bairro Camobi (P4), estrada para a Cidade dos Meninos (Rua Angelin Bortholuzzi). Este ponto recebe, além de esgotos, grande quantidade de resíduos sólidos que podem ser observados ao entorno de suas margens. Outro local de amostragem (P5) teve como localização o Distrito de Arroio do Só localizado ao leste da cidade, que sofre influência de atividades agrícolas, especialmente cultura de arroz. Foi escolhido também um ponto (P6) na área da cidade Universitária em um curso d'água da sub-bacia do Lagoão do Ouro, que serve como receptor de grande parte do esgoto produzido no Bairro Camobi. 


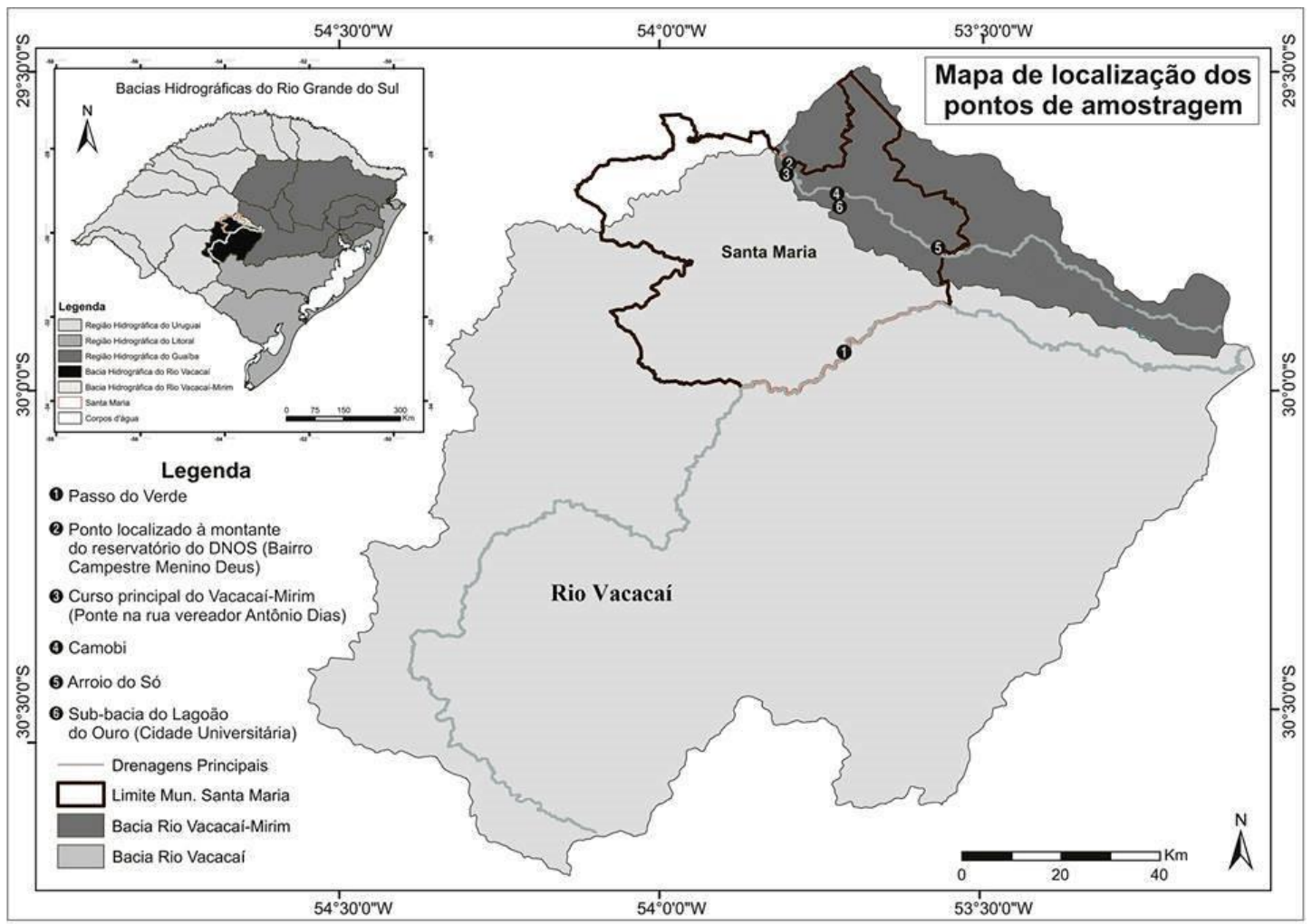

Figura 1. Localização dos seis pontos de amostragem, na bacia hidrográfica dos Rios Vacacaí e Vacacaí-Mirim no Estado do Rio Grande do Sul, Brasil. Os pontos 3, 4 e 6 correspondem a áreas urbanas.

\subsection{Procedimentos de coleta e análise}

As coletas das amostras de água foram realizadas mensalmente de junho de 2011 a maio de 2012, nos seis pontos de amostragem descritos acima. A concentração de oxigênio dissolvido e a temperatura da água foram determinadas no local da coleta com o auxílio de um oxímetro modelo Q-758P. Foram coletados aproximadamente cinco litros de água para as análises laboratoriais. As médias mensais de precipitação pluviométrica para o município de Santa Maria foram obtidas do portal INMET (INMET 2012). A parte analítica foi realizada no Laboratório de saneamento junto ao departamento de Engenharia Sanitária e Ambiental/UFSM, onde foram realizadas as análises de condutividade elétrica, $\mathrm{pH}, \mathrm{DBO}$, $\mathrm{DQO}$, sólidos totais, turbidez e temperatura da água.Todos os procedimentos analíticos foram realizados de acordo com APHA (1998).
A condutividade elétrica da água e o $\mathrm{pH}$ foram determinados com um condutivímetro/potenciômetro, modelo WTW Inolab Oxivel 2. A turbidez foi determinada com o auxílio de um turbidímetro modelo OrbecoHellige 966. A determinação de DBO foi feita pelo Método Modificado de Winkler, (APHA, 1998). A DQO foi determinada através do método do refluxo fechado (APHA, 1998). Para a determinação dos sólidos em suspensão foi utilizado o método gravimétrico, após filtragem das amostras utilizou-se membranas de celulose $(0,45 \mu \mathrm{m})$ Millipore de acordo com APHA (1998).

Os resultados das variáveis de qualidade da água foram comparados com as classes para diferentes usos da água, de acordo com a Resolução CONAMA n.357 (BRASIL, 2005).

Para se identificar o efeito das variáveis abióticas nos seis pontos de amostragem aplicouse técnica de estatística multivariada de Análise 
da Componente Principal (ACP). Com a análise de ACP pretendeu-se detectar inter-relações entre as variáveis ambientais analisadas, condensando sua informação em um conjunto menor de variáveis, também conhecidos como fatores e com isso diminuir a perda de informações (HAIR, 2009). A matriz de dados foi composta por 576 valores (8 variáveis amostradas em 6 pontos, de junho de 2011 a junho de 2012). Foi utilizado o programa PCORD, versão 5.0 (MCCUNE; MEFFORD, 1999).

\section{Resultados e discussão}

$\mathrm{Na}$ figura 2 está representada a precipitação mensal para o período mencionado.

Verifica-se que na maior parte do período de estudo, teve-se condições tipicamente anormais com baixas precipitações. Esta situação foi ainda mais crítica nos meses de novembro, dezembro e janeiro, quando as temperaturas estavam bastante elevadas e teve-se os menores índices pluviométricos. Neste período ocorreram em alguns pontos a morte de peixes observado 'in loco'. De acordo com Souza (2001) a média histórica para todo o mês de janeiro, em Santa Maria é 141,1 mm, acima do observado para janeiro de 2012. Todas as coletas foram realizadas em período seco e os dados pluviométricos correspondem ao período entre cada coleta.

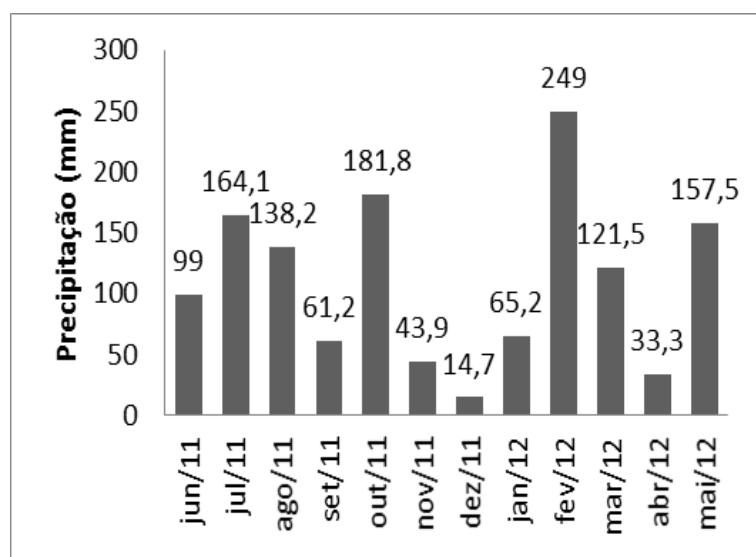

Figura 2. Histograma de precipitação mensal - Santa Maria -RS.

A temperatura da água apresentou valores que variaram de $11^{\circ} \mathrm{C}$ à $26^{\circ} \mathrm{C}$. Os menores valores foram registrados no inverno, principalmente nos meses de junho e julho e os maiores nos meses de janeiro e fevereiro, correspondente ao período do verão. A estatística descritiva dos dados encontra-se na Tabela 1.

Para definir a qualidade da água de mananciais hídricos, os corpos d'água foram enquadrados em classes para diferentes usos da água, de acordo com a Resolução CONAMA n.357 (BRASIL, 2005).

A seguir são apresentados os resultados dos parâmetros medidos, com discussão e comentários separadamente, por variável.

Tabela 1 - Valores médios \pm desvio padrão; mediana; valores mínimos e máximos respectivamente, das variáveis da qualidade da água em 6 estações de amostragem na Bacia Hidrográfica do Vacacaí, município de Santa Maria, RS, durante 12 meses de amostragem: junho/2011 a junho/2012.

\begin{tabular}{|c|c|c|c|c|c|c|}
\hline Variáveis & P1 & P2 & P3 & P4 & P5 & P6 \\
\hline \multirow[t]{3}{*}{$\mathrm{OD}\left(\mathrm{mg} \mathrm{L}^{-1} \mathrm{O}_{2}\right)$} & $9,17 \pm 3,2$ & $10,6 \pm 2,2$ & $10,0 \pm 3,1$ & $6,9 \pm 2,7$ & $7,5 \pm 3,4$ & $2,1 \pm 1,2$ \\
\hline & 9,2 & 10,7 & 10,2 & 8,2 & 8,1 & 1,8 \\
\hline & $2,9-13,5$ & $7,1-13,6$ & $7-13,8$ & $1,9-9,7$ & $1,7-12,2$ & $0,4-4,8$ \\
\hline \multirow[t]{3}{*}{$\mathrm{DBO}\left(\mathrm{mg} \mathrm{L}^{-1} \mathrm{O}_{2}\right)$} & $1,97 \pm 0,8$ & $1,34 \pm 0,8$ & $1,29 \pm 0,5$ & $7,9 \pm 9,2$ & $10,0 \pm 10,2$ & $41,4 \pm 13,4$ \\
\hline & 1,7 & 1,1 & 1,3 & 5,2 & 3,7 & 44,5 \\
\hline & $0,90-3,8$ & $0,23-3,26$ & $0,42-2,52$ & $1,9-35,0$ & $1,2-30,4$ & $24,5-70,3$ \\
\hline
\end{tabular}




\begin{tabular}{|c|c|c|c|c|c|c|}
\hline \multirow[t]{3}{*}{$\mathrm{DQO}\left(\mathrm{mg} \mathrm{L}^{-1} \mathrm{O}_{2}\right)$} & $20,13 \pm 20,1$ & $7,5 \pm 4,9$ & $7,1 \pm 5,4$ & $27,6 \pm 14,0$ & $22,1 \pm 17,2$ & $79,5 \pm 25,4$ \\
\hline & 20,2 & 3,7 & 5,2 & 29,1 & 12,1 & 85,9 \\
\hline & $6,7-43,4$ & $1,8-32,9$ & $1,1-19,3$ & $5,5-45,9$ & $3,7-59,7$ & $40,6-116,3$ \\
\hline \multirow{3}{*}{$\begin{array}{l}\text { Condutividade - } \\
\mu \mathrm{S} \mathrm{cm}{ }^{-1}\end{array}$} & $94,6 \pm 27,5$ & $101,07 \pm 20,8$ & $112,2 \pm 27,8$ & $261,5 \pm 87,8$ & $116,1 \pm 56,3$ & $443,9 \pm 163,6$ \\
\hline & 95 & 97,1 & 105,7 & 265,5 & 101,7 & 418,5 \\
\hline & $58,6-143,3$ & $80,5-140,7$ & $81,6-160$ & $99,2-395$ & $61,4-249$ & $166,8-686$ \\
\hline \multirow[t]{3}{*}{ Turbidez (uT) } & $54,09 \pm 20,4$ & $24,07 \pm 30,5$ & $9,64 \pm 6,8$ & $26,4 \pm 46,4$ & $54,7 \pm 45,1$ & $33,3 \pm 20,9$ \\
\hline & 48,1 & $\overline{9,2}$ & 7 & 11,4 & 33 & 26,4 \\
\hline & $27-84$ & $4,1-102,1$ & $3,9-25,5$ & $6,1-173$ & $20,3-158,2$ & $12,9-86,8$ \\
\hline \multirow{3}{*}{$\begin{array}{c}\text { Sólidos } \\
\text { Suspensos (UT) }\end{array}$} & $53,2 \pm 74,2$ & $22,8 \pm 40,3$ & $25,1 \pm 38,1$ & $33,3 \pm 73,1$ & $50,5 \pm 54,6$ & $25,1 \pm 23,7$ \\
\hline & 33,9 & 8,2 & 9,2 & 12,5 & 28 & 17,1 \\
\hline & $5-284$ & $1-133$ & $3,1-135$ & $3,5-264,0$ & $7,3-185$ & $8,5-94$ \\
\hline \multirow[t]{3}{*}{$\mathrm{pH}$} & $7,0 \pm 0,4$ & $7,3 \pm 0,1$ & $7,2 \pm 0,2$ & $7,1 \pm 0,2$ & $7,0 \pm 0,3$ & $7,2 \pm 0,3$ \\
\hline & 7,1 & 7,3 & 7,3 & 7,2 & 6,9 & 7,3 \\
\hline & $6,0-7,0$ & $6,6-7,1$ & $6,8-7,6$ & $6,8-7,6$ & $6,6-7,9$ & $6,6-7,8$ \\
\hline \multirow{3}{*}{$\begin{array}{l}\text { Temperatura } \\
\left({ }^{\circ} \mathrm{C}\right)\end{array}$} & $20,6 \pm 6,4$ & $17,2 \pm 4,1$ & $17,7 \pm 4,7$ & $19,2 \pm 5,4$ & $20,1 \pm 5,9$ & $20,4 \pm 4,6$ \\
\hline & 20,7 & 17,2 & 17,7 & 19,2 & 20,2 & 20,3 \\
\hline & $11-25$ & $12,4-23$ & $12,5-25$ & $13-26$ & $13-26$ & $14-26$ \\
\hline
\end{tabular}

\subsection{Oxigênio dissolvido}

Os valores médios de OD variaram de 2,1 no ponto 6 a 10,6 no ponto 2, como apresentados na tabela 1 . Na figura 3 mostram-se as concentrações de oxigênio dissolvido para as 12 campanhas de amostragem. Observou-se um decaimento destas concentrações nos meses de janeiro, fevereiro e março, período em que pode ser observada uma elevação dos valores de DBO e DQO e temperatura.

O ponto 6, durante 7 coletas teve seus valores de OD inferiores a $2 \mathrm{mg} / \mathrm{L}$, ficando abaixo do estabelecido para a classe 4 da resolução do Conama que determina que seus valores não sejam inferiores a 2 . Os demais pontos na maioria de suas coletas tiveram valores não inferiores a $6 \mathrm{mg} / \mathrm{L}$, estabelecido para a classe 1 da resolução do Conama. O ponto 6 localiza-se em uma área que recebe grande aporte de matéria orgânica que provém de esgotos urbanos do Bairro Camobi. Os valores de OD foram em geral bastante elevados, provavelmente devido à ação da rápida correnteza observada nos locais, bem como em geral baixa profundidade.

\subsection{Demanda bioquímica de oxigênio}

Os valores variaram de 0,23 $\mathrm{mg} / \mathrm{L}$ registrado no ponto 2 na coleta de junho de 2012 a $70,3 \mathrm{mg} / \mathrm{L}$ registrado do ponto 6 na coleta de setembro de 2011. Os maiores valores médios de DBO foram verificados nos pontos 4, 5 e 6, evidenciados na tabela 1.

$\mathrm{Na}$ figura 3 mostram-se os valores da demanda bioquímica de oxigênio para as campanhas de monitoramento em todos os locais 
de coleta. Os pontos 1, 2 e 3 em todas as coletas indicaram valores inferiores aos estabelecidos para a classe 1 da Resolução CONAMA 357/05 (3 $\mathrm{mg} / \mathrm{L})$, entretanto os demais pontos apresentam valores que superam este limite e coincidem com os que apresentaram baixas concentrações de OD. O ponto 6 durante todas as coletas apresentou valores estabelecidos para a classe 4 dessa resolução.



Figura 3. Variáveis de qualidade da água analisadas durante 12 meses em 6 pontos de amostragem da Bacia Hidrográfica do Vacacaí.

\subsection{Demanda química de oxigênio}

Nos valores da DQO observou-se um gradiente de variação, com tendência a elevação de seus valores de trechos superiores para os inferiores. Foi registrado um valor mínimo de 1,1 mg/L em fevereiro de 2012 no Ponto 3, semelhante aos valores observados no ponto 2 e um valor máximo de 116,3 mg/L no ponto 6 no mesmo período. A DQO também teve seus maiores valores médios encontrados nos pontos 4,5 e 6 como evidenciado na tabela 1 . Esses pontos são os que apresentam maior influência das atividades humanas, como o lançamento direto de esgotos e resíduos sólidos que são depositados ao seu entorno, observado 'in loco' o que justifica sua maior carga de matéria orgânica e consequentemente menor quantidade de oxigênio dissolvido.

Comparando diferentes meses, percebe-se pela figura 3 que os valores máximos de DQO ocorreram em datas diferentes dos máximos de DBO, indicando possíveis diferenças na composição dos contaminantes, sendo que estes processos medem diferentes formas de oxidação na água.

\subsection{Condutividade elétrica}

O menor valor registrado de CE foi de $158,6 \mu \mathrm{S} \mathrm{cm} \mathrm{cm}^{-1}$ para o ponto 1 e o valor máximo foi de $686,0 \mu S \mathrm{~cm}^{-1}$ para o ponto 6. Houve a 
tendência de aumento desse parâmetro nos meses de novembro, dezembro e janeiro (2011/12), possivelmente pelo aumento da temperatura. De acordo com Carvalho et al. (2000) a relação entre aumento da temperatura e condutividade elétrica na água, pode ocorrer em virtude de reações desencadeadas na fauna aquática, em virtude do aumento da temperatura.

\section{$3.5 \mathrm{pH}$}

Os valores de $\mathrm{pH}$ para os pontos 1 e 2 tiveram seus valores entre 6 e 7,1 e nos demais pontos seus valores ficaram entre 6,6 e 7,9. Percebe-se valores de $\mathrm{pH}$ aceitáveis para o padrão do Conama pois todas as amostras estão dentro dos limites estipulados como ideais segundo as normas da Conama 357/05, que é de 6 a 9. Valores semelhantes também foram encontrados por Marchezam (2009) para os mesmos rios.

\subsection{Turbidez e Sólidos suspensos}

De acordo com a tabela 1 os valores médios de turbidez e sólidos suspensos por pontos, mostraram tendência semelhante. Nos pontos 1 e 5, respectivamente, foram registrados os maiores valores. Esses locais correspondem às amostragens realizadas nos maiores afluentes

Dentre os valores de Turbidez, os pontos 2 e 3 apresentaram valores permitidos na Resolução do Conselho Nacional de Meio Ambiente-CONAMA 357/05 (águas de classe I a turbidez deve ser no máximo de 40 NTU), valores acima do limite estabelecido devem-se, provavelmente, a grandes quantidades de partículas erodidas do solo no período chuvoso. Os demais pontos tiveram valores variáveis, desde a classe 1 até a classe 4 . Esta resolução não dispõe sobre limites para sólidos suspensos. De acordo com Von Sperling (2005) quando a turbidez for igual a $10 \mathrm{uT}$, pode-se visualizar uma pequena nebulosidade, já uma turbidez igual a 500 uT, a água é praticamente opaca.

Com relação aos parâmetros analisados, o ponto 6 enquadra-se na classe 4 da resolução do CONAMA 357/05. Segundo esta resolução nesta classe as águas podem ser destinadas apenas para navegação e harmonia paisagística. Os demais pontos tiveram valores estabelecidos principalmente para as classes 1 e 2 do CONAMA. Nestas classes, segundo a resolução as águas podem ser usadas para o consumo humano após desinfecção, para a preservação do equilíbrio natural das comunidades aquáticas, pode também ser utilizado para recreação de contato primário, para irrigação de hortaliças e proteção das comunidades aquáticas.

\subsection{Análise de componentes principais}

A análise de componentes principais (ACP) foi realizada com intuito de avaliar as mudanças espaciais e temporais com relação às variáveis de qualidade da água nos diferentes pontos de monitoramento. Esta análise permite a redução do número de variáveis facilitando a obtenção de informações mais relevantes na avaliação da qualidade da água (ANDRADE et al., 2007). Os valores elevados dos pesos fatoriais sugerem quais são as variáveis mais significativas em cada eixo.

De acordo com a ACP (Figura 4) ocorreu uma associação espacial dos parâmetros em relação às amostragens.

A componente principal 1 explicou $43,59 \%$ da variância e apresentou forte contribuição das variáveis, condutividade $(0,4366), \quad \mathrm{DBO}_{5} \quad(0,4769), \quad \mathrm{DQO} \quad(0,4659)$ e temperatura $(0,2959)$ foram positivamente relacionadas com o primeiro eixo, enquanto que o OD $(-0,4864)$ esteve negativamente associado.

Observa-se que a ocorrência da maioria das amostragens efetuadas nos pontos 4, 5 e 6, correspondentes a trechos inferiores estão associadas às variáveis, $\mathrm{DBO}_{5}$, DQO, condutividade e temperatura. Já os pontos 1, 2 e 3, localizados em trechos superiores, estão associados a valores mais elevados de oxigênio dissolvido. A $\mathrm{DBO}_{5}$ e OD apresentam correlação inversa, uma vez que seus pesos aparecem em quadrantes opostos. Essa relação está de acordo com a dinâmica química dos sistemas aquáticos envolvendo o processo de consumo de oxigênio para degradação da matéria orgânica. Dessa forma percebe-se a presença de um gradiente ambiental evidenciando menores níveis de poluição orgânica em trechos superiores, com 
tendência a aumento desses parâmetros em trechos inferiores

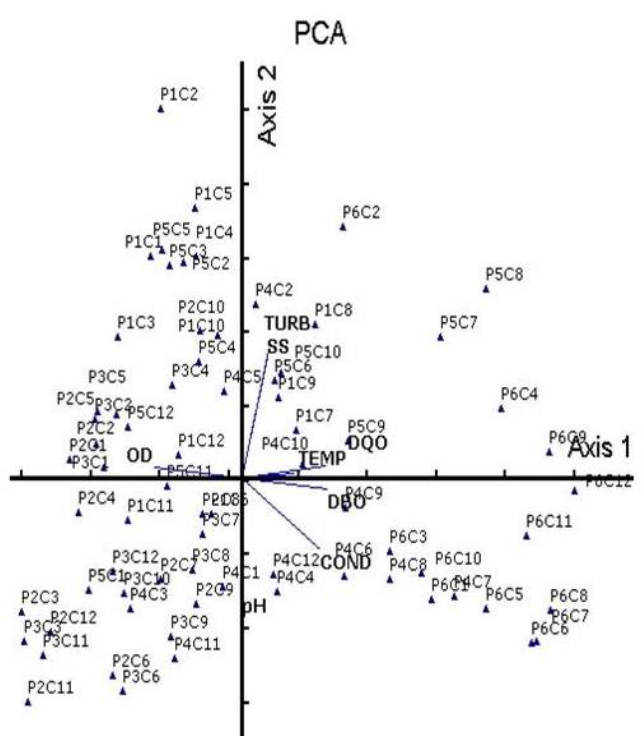

Figura 4. Análise de componentes principais (PCA), relacionando as amostragens realizadas nos 6 pontos, durante 12 meses com as variáveis ambientais.

A componente principal 2 explicou $24,6 \%$ do total da variância. As variáveis de maior peso foram o $\mathrm{pH}(-0,5239)$, a turbidez $(0,5718)$ e sólidos suspensos $(0,5359)$. O pH teve relação principalmente com algumas coletas do ponto 2 e 3 que tiveram valores levemente maiores. Já o ponto 1 e 5 em algumas coletas apresentaram valores maiores de turbidez e sólidos em suspensão, esses pontos correspondem aos maiores afluentes e locais onde pode-se observar um acelerado processo de erosão em suas margens decorrentes do desmatamento de matas ciliares e também de prática agrícola muito próximo ao leito do rio. Segundo Lopes et al. (2005) os diferentes usos do solo levam a diferentes graus de exposição deste, favorecendo a incidência de processos erosivos, que carreiam o material particulado para os cursos d'água, comprometendo sua qualidade devido ao aumento da turbidez.

Os parâmetros de qualidade da água que melhor diferenciaram os pontos estão relacionados com a poluição orgânica indicando a degradação da qualidade da água como consequência da urbanização e lançamento de esgoto na área, fato também observado por Brites (2005) para outras duas bacias hidrográficas do município de Santa Maria
4 Conclusão

Com os dados obtidos, observa-se um maior comprometimento da qualidade da água em locais mais urbanizados da Bacia Hidrográfica, que apresentou as concentrações médias mais elevadas, em termos de $\mathrm{DBO}_{5}, \mathrm{DQO}$ e condutividade elétrica, em comparação a locais menos urbanizados, sendo que nestes pontos foram observadas concentrações elevadas de OD e mais baixas concentrações médias de sólidos suspensos.

Os resultados levam a concluir que o processo de urbanização e industrialização tem comprometido a qualidade dos recursos hídricos, de enorme importância para a sobrevivência de todos os seres vivos.

A degradação da qualidade da água da Bacia Hidrográfica do rio Vacacaí é pontual e tem como principal origem o processo de urbanização.

\section{Referências}

ANDRADE, E. M. et al. Seleção dos indicadores da qualidade das águas superficiais pelo emprego da análise multivariada. Engenharia Agrícola, v.27, p.683-690, 2007.

APHA, AWWA, WEF. Standard methods for the Examination of water and Wastewater. 20a ed., Public Health Association Inc., New York, 1998.

Brasil. CONAMA - Conselho Nacional do Meio Ambiente: Resolução n0 357. Diário Oficial da União 17/03/2005

Brites, A. P. Z. Avaliação da qualidade da água e dos resíduos sólidos no sistema de drenagem urbana. 2005. Dissertação (Mestrado em Engenharia Civil) Universidade Federal de Santa Maria, Santa Maria, 2005. 
CARVALHO, A.R.; SCHLITTLER, F.H.M.; TORNISIELO, V.L. Relações da atividade agropecuária com parâmetros físicos químicos da água. Química Nova, v.23, n.5, p. 618-622, 2000.

GASTALDINI, M., C., C., DO. et al. Diagnóstico da qualidade da água na bacia hidrográfica do rio Vacacaí Mirim. xxx congreso interamericano de ingeniería sanitaria $y$ ambiental, 2006. Punta Del Este. Anais... Uruguay. 2006.

GUIMARÃES, R. J.; NOUR, A. A. Tratando nossos esgotos: processos que imitam a natureza. Cadernos Temáticos de Química Nova na Escola (Meio Ambiente), n.1, p. 1930, 2001.

Hair, J. F. J. et al. Análise multivariada de dados. 6o edição. Porto Alegre, 2009.

INMET. Instituto Nacional de Meteorologia. Disponível em: $<$ http://www.inmet.gov.br/portal/>. Acesso em: 20 out. 2012.

LIBÂNIO, M. Fundamentos de qualidade e tratamento de água. Campinas, SP: Editora Átomo, 2005.

LOPES, F. W. A. et al. Análise da qualidade da água, Degradação Ambiental e Atividade Turística no entorno da Cachoeira da Fumaça, Carrancas- MG. In: Simpósio Brasileiro de Geografia Física Aplicada, São Paulo: USP. p. 4855-4862, 2005.

MARCHESAN, E. Qualidade de água dos rios Vacacaí e Vacacaí-Mirim no Estado do Rio Grande do Sul, Brasil. Ciência Rural, Santa Maria, v.39, n.7, p.2050-2056, 2009.

MCCUNE, B.; MEFFORD, M. J. PC-ORD for windows (software). Multivariate analysis of ecological data, Version 4.14. MjM Software, Gleneden Beach, OR, USA, 1999.

SEMA. Secretaria do meio ambiente do Estado do Rio Grande do Sul. Disponível em: $<$ http://www.sema.rs.gov.br/>. Acesso em 23 out. 2012.

SOUZA, B.S.P. A qualidade da água de Santa Maria/RS: uma análise ambiental das sub bacias hidrográficas dos rios Ibicuí Mirim e Vacacaí Mirim. 2001. Tese (Doutorado em Geografia)-Universidade Federal de Santa Maria, Santa Maria, 2001.

TAVARES, A.R. Monitoramento da qualidade das águas do rio Paraíba do Sul e diagnóstico de conservação. 2005. 176f. Dissertação (Mestrado Instituto Tecnológico de Aeronáutica-ITA), São José dos Campos, São Paulo. 2005.

VON SPERLING, M. Introdução à qualidade das águas e ao tratamento de esgotos. 3. ed. Belo Horizonte: Departamento de Engenharia Sanitária e Ambiental, 2005. 452p. 